\title{
Impact of employees' character strengths of wisdom on stress and creative performance
}

James B. Avey, Department of Management, College of Business, Central

Washington University

Fred Luthans, Department of Management, College of Business Administration, University of Nebraska

Sean T. Hannah, Army Center of Excellence for the Professional Military Ethic, United States Military Academy

David Sweetman, Department of Management, College of Business Administration, University of Nebraska

Christopher Peterson, Department of Psychology, University of Michigan-Ann Arbor

Human Resource Management Journal, Vol 22, no 2, 2012, pages 165-181

Both conventional understanding and positive psychology recognise an important link between people's character strengths and how they perform their jobs. However, no research to date has focused on the relationship of employees' wisdom strengths, potential mediating effects and creative task performance. Utilising a large heterogeneous sample ( $\mathrm{N}=974)$ of working adults, this study found that participants' levels of the character strengths of wisdom were positively related to their performance on a creative task and negatively related to their reported level of stress. In addition, stress was found to be negatively related to creative task performance, with reported stress partly mediating the relationship between participants' wisdom and their performance on the creative task. Implications for incorporating character strengths in the development of HRM theory and practice conclude the article.

Contact: James B. Avey, College of Business, Central Washington University, 400 E. University Way, Ellensburg, WA 98926, USA. Email: aveyj@cwu.edu

\section{INTRODUCTION}

$\mathbf{W}$ hile the role of positivity in HRM has received some recent attention (e.g. Avey et al., 2009; Tsai et al., 2009), the role of positive psychology (see Seligman and Csikszentmihalyi, 2000) and positive organisational behaviour (see Luthans, 2002; Luthans and Avolio, 2009) has been generally neglected. One area of positive psychology that is potentially relevant to advancing HRM is character strengths (e.g. see Wright and Goldstein, 2007). However, to date, very little empirical research has been devoted to employee character strengths.

This study builds on and extends previous work in positive psychology by Peterson and Seligman (2004) on character strengths. They provided a comprehensive theoretical framework and classification system in which they identified character strengths as the processes and mechanisms that underlie and define one's virtues, enabling individuals to perform and flourish and live the good life. Although character strengths have been recognised to be somewhat general and stable, they have also been found to be 'shaped by the individual's setting and thus capable of change' (Peterson and Seligman, 2004: 10). The relative stability of character traits, and therefore their generalisability across situations, is of particular interest to 
understanding human behaviour and performance in the organisational context (Luthans and Youssef, 2007).

While the topic of character strengths has strong theoretical development in positive psychology (Peterson and Seligman, 2004), little research has been devoted to determining in what ways character strengths relate to various domains of individual performance in the workplace. Peterson and Seligman (2004) stated that any valid science of positive psychology must include the institutions in which individuals are embedded because some work contexts provide 'enabling conditions' (p. 11) for character strengths to develop and be manifest, whereas other contexts preclude them. Thus, a major aim of this study is to contribute to the call for further attention to how character strengths and their consequences might be translated into good work performance (Wright and Goldstein, 2007).

More specifically, this study focuses on the roles wisdom and stress may play in creative task performance. Individual creativity has been described as the process of 'coming up with fresh ideas for changing products, services, and processes so as to better achieve the organization's goals' (Amabile et al., 2005: 367). Both management scholars and practitioners bemoan the lack of creative output by organisational members, and some have suggested more effective HRM may be a solution to this dearth of innovation (Shipton et al., 2006). In any event, a lack of creativity and innovation is widely recognised as one of the top threats to modern organisations, and there is substantial evidence that individual creativity at all levels enables organisations to adjust to changing environments, compete, and survive (Amabile, 1996). While many empirical studies have examined individual creativity and the correlates of personal and contextual factors (e.g. Tierney and Farmer, 2002), this is the first study to examine the relationships among individuals' character strengths of wisdom, stress levels, and creative task performance.

Although the study of wisdom has been considered through the ages (e.g. King Solomon's Old Testament book of Proverbs), it has recently received increased attention in positive psychology. Specifically, in this study we draw on the extensive work by Peterson and Seligman (2004). According to their classification system, people can possess six primary virtues, each composed of underlying character strengths. Wisdom is one of these virtues and is defined by the five underlying character strengths of perspective, judgement, originality, curiosity, and love of learning. They state that wisdom encompasses positive traits related to the acquisition and use of information in the service of the good life. That is, wisdom is antecedent to desired cognitive outcomes, such as creative performance (Peterson and Seligman, 2004). The present research examines the direct relationship between wisdom and creative task performance as well as how contextual factors (in this case a task demand) influence stress that may in turn affect individuals' creative task performance.

A stressful context where individuals feel overworked causes a state of attention deficit. The symptoms of dysfunctional stress include 'distractibility, inner frenzy, and impatience' (Hallowell, 2005: 56). The mounting work pressures to achieve time and quality improvements promote such stress reactions and undermine the efficacy of traditional models of professional work design (Elsbach and Hargadon, 2006). Compounding the problem is the recent downsizing and massive lay-offs resulting from the economic downturn which has forced survivors to simply do more work with less time and resources. What may be even worse, this 'busyness' and resulting stress has seemed to become a status symbol in many organisations. Chajut and Algom (2003: 231) noted that while 'it is difficult to overstate the practical significance of resolving the question of performance under stress', as Hunter and Thatcher (2007) pointed out, there is still much to be learned concerning the relationship between stress and performance. Based on theories of psychological resources (Fredrickson, 
2001; Hobfoll, 2002), we propose that the virtue of wisdom may provide employees psychological resources from which to draw from and reduce their stress and in turn enhance their creative task performance. Figure 1 summarises the conceptual model tested in this study.

\section{THE ROLE OF CHARACTER STRENGTHS OF WISDOM ON CREATIVE PERFORMANCE}

There are six overall virtues identified in the Peterson and Seligman (2004) classification: wisdom, courage, humanity, justice, temperance and transcendence. Each of these six virtues has multiple components they called character strengths. These character strengths are the processes or mechanisms that define the virtues.

The present study focused on the virtue of wisdom because it has been identified as a potentially key psychological resource that individuals can draw from to increase their performance and thus has relevant application to the cognitive performance of organisational participants such as creative idea generation (e.g. see Luthans et al., 2007: 151-157). In addition to this role wisdom may play in creative performance, as found in Janis's (1972) classic research on groupthink, stressful experiences lead to increased rigidity, including reduced creative performance. From this point of departure, we propose that employees' wisdom character strengths, with possible mediation effects through decreasing levels of stress, may be related to their creative task performance (see Figure 1).

\section{The wisdom virtue}

As background for the study, an understanding of the properties of the wisdom virtue and its underlying strengths such as creativity, as being distinct from creativity as an outcome, are needed. Peterson and Seligman (2004: 10) take an approach to defining strengths 'in the spirit of personality psychology, and ... trait theory'. Strengths are thus individual differences, which, like traits, serve as the locus or drivers of thoughts and behaviours but are separate from those thoughts and behaviours themselves. Creative task performance is the primary criterion in this study and is considered to be a potential manifestation of the wisdom character strengths. Amabile (1996) argued that the manifestation of creativity can be assessed through focusing on either the level of idea generation or the level of feasibility of those ideas. In this study, and consistent with previous research (e.g. Harrison et al., 2003), we focused on the ideation component of creativity. More specifically, in the early stages of problem solution, brainstorming multiple options may be more important than determining the feasibility of each option. If ideation is limited, there are fewer or zero options to even begin a feasibility or scrutinisation process. Thus, in this study when we say creative task performance is the criterion we separate it conceptually from the strength of originality/creativity as an individual

FIGURE 1 Theoretical model relating wisdom strengths, stress and creative performance

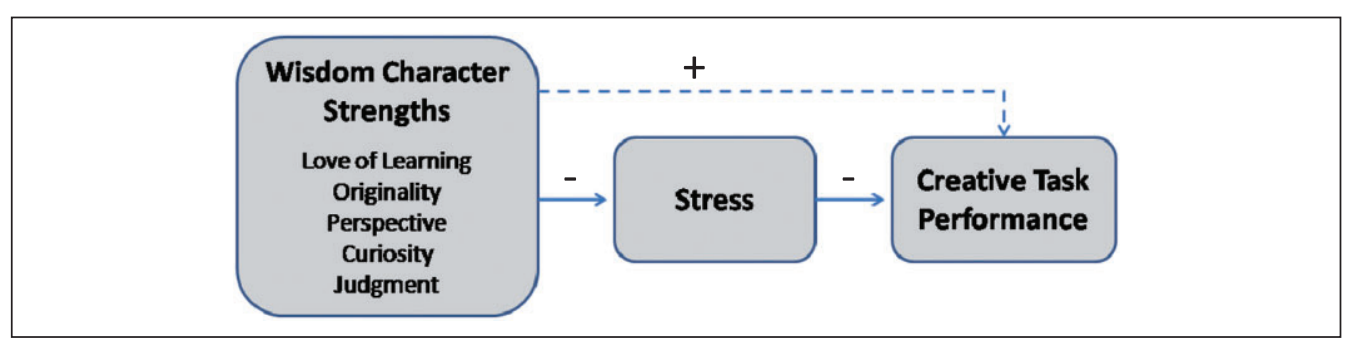


TABLE 1 Summary of character strengths comprising the virtue of wisdom

\begin{tabular}{|c|c|c|}
\hline Strength & Brief description & Example \\
\hline Perspective & $\begin{array}{l}\text { Process of making sense of oneself and } \\
\text { others through using one's accumulated } \\
\text { knowledge. }\end{array}$ & $\begin{array}{l}\text { Offering advice to a junior team } \\
\text { member based directly on similar } \\
\text { personal experiences. }\end{array}$ \\
\hline Judgement & $\begin{array}{l}\text { Process of being broad-minded, open- } \\
\text { minded, flexible and complex in } \\
\text { approaching change. }\end{array}$ & $\begin{array}{l}\text { Keeping an open mind and actively } \\
\text { considering options when presented } \\
\text { with a change. }\end{array}$ \\
\hline Originality & $\begin{array}{l}\text { Creation of novel, surprising or unusual } \\
\text { ideas. }\end{array}$ & $\begin{array}{l}\text { Brainstorming ideas for developing a } \\
\text { new product. }\end{array}$ \\
\hline Curiosity & $\begin{array}{l}\text { Intrinsic interest and openness to ongoing } \\
\text { experiences. }\end{array}$ & $\begin{array}{l}\text { Trying cartoons to demonstrate points } \\
\text { in a staff meeting to get the group's } \\
\text { reaction. }\end{array}$ \\
\hline $\begin{array}{l}\text { Love of } \\
\text { learning }\end{array}$ & $\begin{array}{l}\text { Drive to acquire knowledge to interact } \\
\text { competently with the world, including } \\
\text { the self-regulation to persevere. }\end{array}$ & $\begin{array}{l}\text { Attending a workshop to develop a } \\
\text { professional skill. }\end{array}$ \\
\hline
\end{tabular}

difference factor, and rather (consistent with our operationalisation) as actual behavioural performance on a creative task exercise requiring the generation of ideas as potential solutions. Therefore, while Peterson and Seligman refer to the wisdom character strength of 'creativity (originality, ingenuity)', which is a key predictor in the study, to avoid confusing constructs (e.g. creativity as a predictor and creative task performance as a criterion) we will use the term 'originality' to denote the strength of creativity (originality/ingenuity).

Given these connections from theory and previous research, the wisdom virtue seems especially relevant as a potential locus of creative task performance. We next turn to a detailed discussion of each of the five strengths of wisdom: perspective, judgement, originality, curiosity and love of learning (Peterson and Seligman, 2004), as summarised in Table 1.

Originality To be considered original, Peterson and Seligman (2004) noted that an idea must be novel, surprising or unusual. Individuals with high levels of originality seem to generate high levels of creativity (Mumford and Gustafson, 1988; Perry-Smith, 2006). It follows that those with high levels of originality would generate original, novel, and unusual ideas and should perform better on creative tasks.

Curiosity This strength of wisdom involves a person's desire to pursue experiences (Peterson and Seligman, 2004). There is considerable support linking the aspects of curiosity to creativity. For example, intrinsic motivation has been found to be an antecedent to creativity (Shalley et al., 2004). Additionally, Baer and Oldham (2006) found a positive relationship between openness to experience (i.e. curiosity) and creative performance in those organisational contexts that are supportive of creativity. Moreover, curiosity has specifically been found to be positively associated with intelligence and problem-solving ability (Peterson and Seligman, 2004).

Judgement This wisdom strength involves the ability to use a more balanced and objective mindset when engaging in complex problem solving (Peterson and Seligman, 2004). Relevant theory building suggests there is a relationship between individuals' cognitive style and their creativity (Amabile, 1996). For example, open-mindedness towards change, combined with 
broader styles of thinking through possibilities, has in turn been shown to lead to the generation of more creative outcomes (George and Zhou, 2001).

Love of learning This wisdom strength is embodied in one's drive to competently interact with the world, including the self-regulation to persevere in gaining knowledge, and through having a sense of possibility (Peterson and Seligman, 2004). This might explain why participation in both training and teaching opportunities can be positively related to one's creativity (Basadur et al., 1982). By more fully understanding and interacting with the world, individuals are more flexible in absorbing new information and in seeking out new situations that build experiences, which are in turn related to increased creativity (Shalley et al., 2004).

Perspective A person with this strength has what Peterson and Seligman (2004: 106) refer to as 'taking stock of life in large terms, in ways that make sense to oneself and others'. The outcome of this knowledge and experience is improved well-being. This strength of perspective has been found to be associated with creativity because it involves the examination of an idea through many different lenses of experience (Shalley et al., 2004). The introspective abilities of perspective enable one to see an idea in different ways, generate permutations of those ideas, and thus produce more possibilities for consideration. Ultimately, such perspective may lead to a more creative outcome based on a greater breadth of options.

\section{Dynamics of wisdom strengths in promoting creativity}

Although each of the above five character strengths is presented individually, Peterson and Seligman (2004) theorise that there is considerable interaction and influence between strengths in the formation of the overall virtue of wisdom. Thus, when evaluating the potential effect of these character strengths on outcomes, it should be conducted using wisdom as a latent construct. This view of the interaction of strengths in the promotion of the wisdom virtue is also consistent with hierarchical and dynamic models of personality which do not lend themselves to a reductionist approach (e.g. Mischel and Shoda, 1998; Dweck et al., 2003). These dynamic models of personality suggest that personality dispositions are manifest in various facets of encoding categories, expectancies, goals, values, affects, and self-regulatory plans which activate to guide individuals' thoughts and behaviours (Mischel and Shoda, 1998). Specifically, emerging theory describes how the activation of positive psychological states and traits of individuals in the workplace may become manifest through such dynamic psychological processes (Hannah and Luthans, 2008; Hannah et al., 2009).

Such a dynamic view of personality would suggest that those with greater levels of wisdom would be prone to activating encoding categories, expectancies, goals, values, affects, and self-regulatory plans that combine to promote creative thought and performance. For example, personality has been shown to influence both efficacy and goal setting (Phillips and Gully, 1997), and goal-directed regulation has in turn been linked to meta-cognitive ability and learning (Schmidt and Ford, 2003). Indeed, research has demonstrated over the years that goals determine the direction, intensity, and duration of efforts (Locke and Latham, 1990). Therefore, we suggest that wisdom would promote increased engagement of intellectual resources, resulting in enhanced performance on a creative task.

In summary, there is considerable theory and research indicating conceptions of cognitive capacity and ability to influence self-regulatory mechanisms that promote complex decision making (e.g. Wood and Bandura, 1989). There is further evidence that dynamic self-regulatory systems are grounded in individuals' self-concepts (Lord and Brown, 2004) such as individuals' mental representations of their strengths and virtues. Specifically, when individuals see 
themselves as possessing high levels of a certain character trait or virtue (e.g. wisdom), they are inherently driven by cybernetic self-regulatory processes to manifest those central aspects of their self-concepts in behaviours (Lord and Brown, 2004; Hannah and Luthans, 2008). Therefore, we propose that greater levels of the virtue of wisdom, through cognitive and affective processes such as the activation of efficacy and goal structures, will therefore promote and regulate one's cognitive efforts more purposively and effectively in performing creative tasks. Given that prior research has not investigated the relationship between the strengths of wisdom and creative performance outcomes, in this study we test the following unique hypothesis:

\section{Hypothesis 1: Wisdom virtue as a whole is positively related to individuals' creative task} performance.

As indicated, while there is little empirical evidence linking strengths to outcomes, particularly creativity, we felt it would be important to also explore whether the five individual strengths underlying wisdom might have differential effects on creative performance, either separately or in differing combinations. Thus, in this study we also explored the research question asking what the relationships are of each of the five individual strengths of wisdom with stress and creativity.

\section{ROLE OF STRESS IN INDIVIDUAL CREATIVITY}

In proposing the relationship between wisdom and performance on a creative task, we recognise that there are other facets, e.g. one's level of stress that may play a role in such a complex process. Specifically, given that theory explains the processes and mechanisms of how and why phenomena occur, the purpose of this section is to explore stress as one possible mechanism that might explain how wisdom is related to creativity beyond a main effect. Although employee stress has received considerable attention in both the academic and popular literature, and there is little question that it leads to nervousness, tension, and strain that negatively affects employees' well-being and performance (e.g. Cooke and Rousseau, 1984), the specific role of stress as a potential factor limiting individual creativity has received little attention.

\section{Effect of stress on individual creativity}

Stress is a cognitive-affective state that occurs when an individual perceives that the demands of an external situation are beyond his or her perceived ability to cope (Lazarus, 1966). Stress should be considered both by form and by level. The effect of stress on performance may be best represented by a curvilinear, inverted U-shaped relationship. Specifically, a minimal amount of stress may be beneficial (i.e. eustress) to help maintain vigilance, excitement and focus up to a certain level or point in time. However, beyond a threshold point stress may become debilitating and exhibit non-linear detrimental effects on performance (Nelson and Sutton, 1990). For the purpose of this study, we define and operationalise stress as distress, or stress that has reached a level at which it exhibits negative effects on cognitive performance, such as on a creative task.

Previous research has suggested that participants in today's organisations may underperform through a lack of creativity due to the stress imposed by intense workload pressures (Amabile et al., 1996; Hallowell, 2005). In fact, Amabile et al. (2002) found that workload and time pressure, combined with frequent interruptions, can reduce employees' creativity by almost half. This might be explained through the possibility that employees in the face of time pressures abandon 
creativity and instead simply copy or extend old ideas instead of spending the time to come up with new ideas and alternative solutions (Baer and Oldham, 2006).

These negative effects of stress become magnified under conditions of acute stress, or stress that Salas et al. (1996) describe as sudden, novel, intense, and relatively short duration that disrupts goal-oriented behaviour and requires a proximate response. Such acute stress negatively affects mental models and transactional memory, explaining poorer performance through information-processing theory (Ellis, 2006). Indeed, in general, one's judgement deteriorates under stress (Staw et al., 1981). Conversely, Bunker (1986) reported that individuals who felt less stress under challenging conditions were generally more optimistic and had a higher tolerance for ambiguity. This process of coping with stress could be experienced by employees when confronted with a novel situation requiring a creative response and idea generation.

Fredrickson (2001) argued that there is a deteriorating effect of stress from negative emotions that lead to increased cardiovascular reaction and a narrowing of thought-action repertoires. Such stress-induced physical reaction and narrowing of thought can lead to a focus on priority information and ignoring of secondary or periphery ideas or tasks, thereby lowering creativity (Ellis, 2006). Furthermore, it has been suggested that stress reduces creativity through increased cognitive rigidity and an associated reduction in tolerance for ambiguity (George, 1986). These various negative impacts of stress lead to our second study hypothesis concerning the effects of stress on creativity:

Hypothesis 2: Individuals' reported level of stress is negatively related to their creative task performance.

\section{Wisdom and reduction of stress}

We propose that the strengths comprising wisdom will promote stress reduction. This is because strengths serve as psychological resources individuals can draw from to enable them to see larger patterns of relationships or meanings, which enhances their understanding of the environment and thus reduces their stress (Fredrickson, 2001; Peterson and Seligman, 2004). Further, wisdom strengths may influence coping strategies that evoke adaptive (versus maladaptive) responses to stress which may direct one's energy away from addressing the source of the stress, or achieving his or her intended purpose (Moos and Schaefer, 1993).

Fredrickson's work on the broaden and build theory (Fredrickson, 2001) has demonstrated that left unchecked, negative emotions narrow the scope of cognition and attention. Negativity limits potential thought-action repertoires, such as idea generation. By the same token, positive emotions broaden thought repertoires under stress. Important to the current study, Fredrickson (2001) holds that positive psychological states and traits can serve as resources that have an 'undoing effect', and 'loosen the hold that a negative emotion has gained on that person's mind and body by dismantling or undoing preparation for specific action' (p. 222). This approach is consistent with Hobfoll's (2002) theory of psychological resources, which proposes that psychological resources can create higher-order 'resource caravans' to draw from to address personal challenges.

Beck et al. (1985) suggest that anxiety, stress, or fear is experienced when the evaluation of a threat or stressor exceeds the evaluation of one's personal resources to face that threat or stressor. Based on the work cited above, we suggest that the strengths of character found in wisdom will provide psychological resources for individuals to draw upon when faced with stress. These strengths provide a sense of efficacy and control as one takes on a novel task, and thereby reduces stress (Fredrickson, 2001; Hobfoll, 2002). 
Previous research has indicated that character strengths associated with the wisdom virtue, e.g. those involving interest and enjoyment in learning, may decrease stress through enabling the individual to find ways to make an otherwise stressful task more enjoyable and interesting (Sansone et al., 1992). This positive process becomes important because experienced stress is most often negatively interpreted as indicative of incompetence, thus reducing self-efficacy and task engagement (Bandura, 1997). Further, such a positive approach has been noted as a critical factor in promoting learning (Hidi and Harackiewicz, 2000). Thus, we derive the third study hypothesis:

Hypothesis 3: There is a negative relationship between individuals' wisdom strengths and their reported level of stress.

\section{Stress as a mediator}

Based on the discussion thus far, we have argued conceptually and research has demonstrated that the wisdom character strengths are grounded in individuals' self-concepts (Mischel and Shoda, 1998; Hannah and Luthans, 2008). We presented that through this process, wisdom strengths influence behaviour through self-regulatory processes (Wood and Bandura, 1989; Lord and Brown, 2004) to drive cognitive performance and creativity. While a direct effect between wisdom and creative performance has already been hypothesised, given the intervening impact of stress described above, we also posit that stress partially mediates this relationship. We base this on the fact that stress is reduced when one believes that he or she has sufficient personal resources to face that threat or stressor (Beck et al., 1985). Through stress reduction, personal resources (Hobfoll, 2002), such as positive personality traits, have an 'undoing effect' on stress, as demonstrated by the work of Fredrickson (2001).

Therefore, the wisdom strengths of originality, curiosity, love of learning, judgement, and perspective would not only be associated with performance on a creative task per se, but inasmuch as these strengths provide perceived resources that reduce stress, would also serve to increase creative thinking by reducing stress and therefore broadening one's realm of ideation (Fredrickson, 2001). This leads to our final study hypothesis:

Hypothesis 4: Individuals' reported level of stress partially mediates the relationship between their wisdom strengths and their creative task performance.

\section{METHOD}

To analyse our research questions and test our study's hypotheses, we conducted a crosssectional design utilising a large $(N=974)$ and heterogeneous sample of working adults from a wide variety of US organisations. The study participants were solicited by electronic mail to volunteer to be included in a Midwestern university-sponsored research project. They were targeted through contacts of management faculty and students at the university. Those who agreed to participate were provided a link to an online secure server. They read and approved the informed consent form and followed the instructions for participation in the study.

Participants had an average age of $33(S D=13.1)$ and were about evenly split in terms of gender (459 males, 417 females, with 98 not reporting). The majority came from organisations with less than 1,000 employees (84 per cent) and ranged in industries from health and human services ( 31 per cent) to financial (11 per cent), marketing ( 6 per cent), construction ( 7 per cent), and others. The majority made less than $\$ 50,000$ per year in annual salary (68 per cent).

Survey instruments measured the independent variables in the study, while performance on a creative task exercise was used as the dependent variable. Specifically, wisdom was measured 
with the Peterson and Seligman (2004) Values in Action Inventory of Strengths (VIA-IS), which is available at http://www.viacharacter.org. Initial psychometric validation of the VIA-IS is described in detail by Peterson and Seligman (2004: 627-633). This measure included items assessing each of the five strengths of interest in the current study including perspective (e.g. 'Have a broad outlook on what is going on'), judgement (e.g. 'Try to identify the reasons for my actions'), originality (e.g. 'Am able to come up with new and different ideas'), curiosity (e.g. 'Find the world a very interesting place') and love of learning (e.g. 'Look forward to the opportunity to learn and grow'). Each of the strengths was measured with 10 items rated on a five-point Likert scale ranging from 'very much unlike me' to 'very much like me'. Peterson and Seligman (2004) reported that all scales had alphas of 0.70 or greater and test-retest correlations over a 4-month period of approximately 0.70. All scales from the VIA-IS in the present study also yielded an internal alpha greater than 0.70 .

A confirmatory analysis was conducted on the VIA-IS used in this study. Specifically, an SEM measurement model was tested where we modelled wisdom as a second-order factor such that each item was fit to each character strength (e.g. Item 1 was fit to the strength of perspective), and each character strength was then fit to the overall wisdom virtue (e.g. perspective, judgement, originality, curiosity and love of learning were fit to the overall wisdom virtue). Overall factor loadings were strong $(40 / 50>0.70,50 / 50>0.5, p<0.01)$ and fit indices $\left[\chi^{2}=3251\right.$ $(d f)=1,136, \mathrm{CFI}=0.92$, RMSEA $=0.04, \mathrm{SRMR}=0.04]$ indicate adequate fit to the data. In addition, each strength loaded on the overall wisdom virtue between 0.71 and $0.85(p<0.01)$ and were intercorrelated between 0.49 and $0.64(p<0.01)$, suggesting a strong (i.e. convergent) relationship but still discrimination between strengths. To ensure the second-order model described by Peterson and Seligman (2004) was psychometrically superior to alternative models, we compared the second-order factor model with a model with all items loading on to one global 'wisdom' factor (e.g. no first-order factors of the character strengths) and with a third model with each item loading to the character strength but no second-order 'wisdom' factor. The hypothesised second-order factor model emerged as a better fit than the first comparison model $\left[\chi^{2}=6,490(d f)=1,150, \mathrm{CFI}=0.47, \mathrm{RMSEA}=0.12, \mathrm{SRMR}=0.20\right]\left[\Delta \chi^{2}=3,239\right.$, $\Delta(d f)=14, p<0.001$ ] and also showed significantly better fit than the second comparison model $\left[\chi^{2}=3,453(d f)=1,131, \mathrm{CFI}=0.91\right.$, RMSEA $=0.05$, SRMR $\left.=0.05\right]\left[\Delta \chi^{2}=202, \Delta(d f)=5, p<0.001\right]$. Thus, overall, the data demonstrated adequate fit to the hypothesised higher-order structure proposed by Peterson and Seligman (2004).

Stress was measured with the seven stress items from the Depression, Anxiety, and Stress Scale (Lovibond and Lovibond, 1995). The items described various symptoms of stress and asked participants to rate the frequency that they experienced these sensations in the last 10 days ranging from very often, if not all the time to hardly ever, if ever. Example items are 'I found it difficult to relax' and 'I found myself getting upset by quite trivial things'. This instrument was internally consistent $(\alpha>0.70)$.

Performance on a creative task was measured by results from a brainstorming activity used in previous creativity research by Harrison et al. (2003). This exercise is called 'unusual uses' and focuses on the ideation component of creativity. As indicated in the introductory comments, we use Amabile's (1996) distinction that creativity can be thought of as both idea generation and feasibility of those ideas. Again, consistent with the previous research using this approach (e.g. Harrison et al., 2003), we chose to focus on the ideation component of creativity. This is because in the early stages of the creativity process, brainstorming multiple options of a problem may be more critical to successful outcomes than is determining the feasibility of each option.

Peterson and Seligman (2004: 115) note that this widely used Unusual Uses Test stimulates divergent thinking associated with creativity: 'Divergent thinking is the capacity to generate a 
great variety of responses to a given set of stimuli. Unlike convergent thinking, which aims at the single most correct response, ideational productivity is emphasized'. Consistent with previous organisational behaviour studies that applied this creativity task exercise, we gave participants a very short time frame in order to generate time pressure (and thus stress) and achieve greater variance in the number of solutions (e.g. see Locke, 1982; Harrison et al., 2003). Specifically, study participants were given 30 seconds to brainstorm and list as many potential uses as they could for common household items. Consistent with Harrison et al. (2003) research, the items used were a coffee mug, wire coat hanger, and a shoelace, and each participant was asked to provide potential uses for the set of objects in no particular order. The 30-second time limit was enforced in the set-up of the online exercise. These items are designed to stimulate breadth, cognitive processing, divergent thinking and ideational productivity in a short period of time. They have been found to be a valid indicator of creativity (e.g. see Locke, 1982). Unusual use examples for the coffee mug included a paperweight, a pencil holder and a doorstop. Unusual use examples for the wire hanger included a marshmallow roaster, selfdefence weapon and TV antenna. Unusual use examples for the shoelace included a finger-tie reminder, a belt and a briefcase handle. The score used was a single index reflecting the total number of ideas generated.

\section{RESULTS}

Means, standard deviations, bivariate correlations and scale reliabilities for all study variables are shown in Table 2. Given the data were continuous in nature and hypothesis tests assessed the relations among continuous variables, we determined that regression was the most appropriate analytical tool. Following the method used by Peterson and Seligman (2003), we calculated a composite measure of the five wisdom character strengths and used regression to test the hypotheses. The results supported Hypothesis 1, which predicted that wisdom was positively related to performance on a creative task $(r=0.15, p<0.001)$.

Hypothesis 2 indicated that individuals' reported stress would be negatively related to their performance on the creative task. As shown in Table 2, stress was negatively related to creative

TABLE 2 Means, standard deviations, bivariate correlations, and reliabilities of study variables ${ }^{\mathrm{a}, \mathrm{b}, \mathrm{c}, \mathrm{d}}$

\begin{tabular}{|c|c|c|c|c|c|c|c|c|c|}
\hline & Mean (SD) & 1. & 2. & 3. & 4. & 5. & 6. & 7. & 8. \\
\hline 1. Wisdom virtue & $3.78(0.52)$ & $(0.96)$ & & & & & & & \\
\hline 2. Stress & $2.84(1.1)$ & -0.20 & $(0.91)$ & & & & & & \\
\hline 3. Creative task performance & $3.38(2.1)$ & 0.15 & -0.23 & 1.00 & & & & & \\
\hline 4. Curiosity & $3.98(0.62)$ & 0.83 & -0.29 & 0.17 & $(0.89)$ & & & & \\
\hline 5. Love of learning & $3.52(0.77)$ & 0.73 & -0.12 & 0.09 & 0.62 & $(0.88)$ & & & \\
\hline 6. Judgement & $3.88(0.66)$ & 0.79 & -0.16 & 0.12 & 0.54 & 0.51 & $(0.92)$ & & \\
\hline 7. Originality & $3.66(0.72)$ & 0.75 & -0.05 & 0.11 & 0.50 & 0.41 & 0.47 & $(0.93)$ & \\
\hline 8. Perspective & $3.78(0.60)$ & 0.82 & -0.15 & 0.07 & 0.57 & 0.41 & 0.66 & 0.72 & $(0.90)$ \\
\hline \multicolumn{10}{|c|}{$\begin{array}{l}{ }^{a} \text { Cronbach reliability alphas are in the diagonals. } \\
\text { b All correlations greater than } 0.12 \text { are } p<0.001 \text {. } \\
\text { c All correlations greater than } 0.09 \text { are } p<0.01 \text {. } \\
\text { d All correlations greater than } 0.07 \text { are } p<0.05 \text {. }\end{array}$} \\
\hline
\end{tabular}


TABLE 3 The partial mediating effects of stress

\begin{tabular}{|llc|}
\hline & $\begin{array}{l}\text { Creative task } \\
\text { performance }\end{array}$ & \\
& Step 1 $\beta$ & Step $2 \beta$ \\
Wisdom character strengths & $0.15^{* *}$ & $0.10^{*}$ \\
Stress & & $-0.21^{* *}$ \\
Total $R^{2}$ & $0.03^{* *}$ & $0.07^{* *}$ \\
$\Delta R^{2}$ & & $0.04^{* *}$ \\
& & \\
& & \\
$* p<0.01, * * p<0.001$. & & \\
\hline
\end{tabular}

task performance $(r=-0.23, p<0.001)$; and after controlling for wisdom in Step 1 of the regression, stress was still negatively related to creative task performance $(\beta=-0.21, p<0.001)$. Hypothesis 3 held that wisdom would be negatively related to stress. Again, as shown in Table 2, support was found for this hypothesis $(r=-0.20, p<0.001)$.

Hypothesis 4 stated that individuals' level of reported stress would mediate the relationship between their wisdom character strengths and their performance on the creative task. According to guidelines by Baron and Kenny (1986), mediation is said to exist when several conditions are satisfied. First, the independent variable must be related to the dependent variable. Next, the independent variable must be related to the mediating variable. The third is that the mediating variable must be related to the dependent variable. Finally, for mediation to exist, the relationship between the independent variable and the outcome variable(s) should be non-significant or reduced when the mediating variable is entered in the model. Given this criteria, tests from Hypotheses 1-3 indicate that the independent variable (wisdom) was related to the dependent variable (idea generation creativity) and the mediating variable (stress). In addition, the mediating variable (stress) was related to the dependent variable. Therefore, to determine mediation, we entered the stress variable into Step 2 of a regression model with wisdom predicting creativity. For full mediation, the relationship between wisdom and idea generation would be non-significant. In this case, as indicated in Table 3, results indicate partial mediation by stress, as wisdom maintained a significant but smaller relationship with performance $(\beta=0.10, p<0.01)$.

\section{Exploratory analyses}

Although previous research has focused on a composite view of wisdom being a multidimensional construct comprising the shared variance among each of the five indicators, there also may be value in exploring each individual component as specified in our exploratory research question posed in the introductory comments. We suggest that there may be value in separately analysing each individual component in this study for three reasons. First, there were relatively small effect sizes in the hypothesis tests when using the combined wisdom factor. Second, combined with the variability in predictive validity evident in the correlation matrix (e.g. originality-stress $=p>0.05$, curiosity-stress $=p<0.001$ ) it is likely that some components may be better predictors in the model than others. Third, given the dearth of research testing virtues and employee stress and any type of performance outcomes, a more 
TABLE 4 Component-level hypothesis tests

\begin{tabular}{|c|c|c|c|}
\hline & $\begin{array}{l}\text { Is the component } \\
\text { related to creative } \\
\text { task performance? }\end{array}$ & $\begin{array}{l}\text { Is the component } \\
\text { related to stress? }\end{array}$ & $\begin{array}{l}\text { Does the relationship } \\
\text { with creative task } \\
\text { performance change with } \\
\text { stress in the model? }\end{array}$ \\
\hline Curiosity & Yes $\left(r=0.17^{* *}\right)$ & Yes $\left(r=-0.29^{* *}\right)$ & Yes. Partial mediation \\
\hline Love of learning & Yes $\left(r=0.09^{*}\right)$ & Yes $\left(r=-0.12^{* *}\right)$ & Yes. Full mediation \\
\hline Judgment & Yes $\left(r=0.12^{* *}\right)$ & Yes $\left(r=-0.16^{* *}\right)$ & Yes. Partial mediation. \\
\hline Originality & Yes $\left(r=0.11^{*}\right)$ & No $(r=-0.05)$ & No \\
\hline Perspective & No $(r=0.07)$ & Yes $\left(r=-0.15^{* *}\right)$ & No \\
\hline
\end{tabular}

comprehensive investigation may reveal future areas of research and understanding. Therefore, in this exploratory analysis, we considered the predictive effects and the stress mediation model using all five components.

As seen in Table 4, originality was not significantly related to stress and perspective was not significantly related to creative task performance. Thus, stress did not mediate the relationship between these two components of creative task performance. However, stress did partially mediate the relationship between both curiosity and judgement and the creative task performance. Further, stress fully mediated the relationship between love of learning and creative task performance. Also evident in Table 4 is the varying magnitude of effect size. Curiosity had nearly twice (or more) the effect on stress as the other four components. In addition, curiosity also showed by far the strongest bivariate relationship with creative task performance. Overall, results from this exploratory analysis suggest that there may be differential effects between the strength components of wisdom, and, at least with these criteria, curiosity seems to be the strongest predictor.

\section{DISCUSSION}

This study had two primary objectives. First, we responded to calls in the fields of positive psychology (Peterson and Seligman, 2004) and organisational studies (Wright and Goldstein, 2007) for further study of the relationship between strengths and individual performance. In one of the first studies using a large sample of employees testing the Peterson and Seligman (2004) virtues, we found support for an empirical link between participants' wisdom strengths and their performance on ideation creativity during a task exercise. These results provide a platform and point of departure for researchers to begin further study of how wisdom strengths may potentially become manifest in the workplace. In addressing this first objective of the study, these findings suggest that wisdom may 'matter' in terms of individual affect (e.g. stress) and creative behaviours (e.g. idea generation).

Second, this study provided initial support for a partially mediating effect of stress between individuals' wisdom, as a higher-order factor, and their performance on a creative task. Supporting the study hypotheses, stress was found to be negatively related to both wisdom strengths and to creative task performance. Given our focus on distress (rather than eustress) 
in this study, these results are interesting in that they suggest that the individual difference of wisdom is associated with lower levels of reported stress. Overall, this finding has implications for stress researchers because even though stress has been heavily researched, incorporating wisdom may be a new venue to expand the boundaries of the current stress theories, stimulate future stress research, and provide guidelines for applications for combating escalating stress in today's workplace.

A closer examination of the data on the individual strengths in Table 2 reveals that while all five wisdom strengths were related to creative task performance - and with the exception of originality were also related to stress - the relatively stronger relationship of the strength of curiosity with both stress and task performance relative to the other strengths examined in this study should be noted. Considering this curiosity-stress relationship post hoc, given the heightened ability of curious individuals to self-regulate (Sansone et al., 1992), it may follow that such individuals are better able to self-regulate their emotional responses to their environment. This self-regulation, in turn, may lessen their level of felt stress, resulting in better creative performance.

Despite this interesting finding specifically related to curiosity, we restate that both theory (Peterson and Seligman, 2004) and our measurement model testing in this study suggest wisdom is a latent construct. It is formed through all five strength factors and their conjoint influences. However, we would add that, at least in this study, curiosity was one of the stronger predictors. Future research will need to apply these wisdom strengths across different samples and contexts in order to ascertain whether a pattern in the magnitude of prediction within and between the individual wisdom strengths on multiple criteria exists.

\section{Theoretical and practical implications}

The findings from this study have several important theoretical and practical implications for HRM. First and foremost, the results provide beginning empirical evidence that individuals' wisdom strengths influence their performance on creative tasks. Second, this study's results may help to build on the link in research between creativity and personality in general and character strengths in particular. Additionally, the partial meditational effect of stress provides initial empirical evidence of the link between individuals' wisdom, their stress, and creative performance - a seemingly important process for effective organisations and HRM that needs further understanding and research.

Besides contributing to theory building, the results also have some practical implications for managing human resources. For example, although creativity is a recognised key to sustained competitive advantage in the global knowledge economy (Amabile, 1996), better understanding the enablers and disablers of creativity is needed. In particular, individuals' strengths may matter most in jobs with high cognitive demands, given this study's findings on the relationship with creative performance and the negative relationship with stress. Thus, a clear application may be the inclusion of wisdom and perhaps other character strengths in employee selection batteries and assessment centres. Further, organisational leaders should attempt to provide environments in which creative associates can thrive and their strengths can be maximised. Indeed, organisations can take a targeted approach to maximise the character strengths of their members (Luthans, 2002; Wright and Goldstein, 2007; Luthans and Avolio, 2009). In particular, the finding demonstrating a partial mediating role of stress between individuals' wisdom and their creative performance underscores the importance of developing environments free of the distressful conditions that may diminish creative performance. In addition, reduction in stress has also been associated with other desired outcomes such as increased team performance (Driskell and Salas, 1991). 


\section{Limitations and future research}

Some limitations need to be noted concerning the findings of this study in relating individuals' wisdom to ideation creativity as mediated by reduced stress. In terms of methods, this study utilised a cross-sectional design and did not subject individuals to experimental manipulations, thus limiting our confidence in causal conclusions. In addition, self-selection bias of study participants could have affected the results. Future research should utilise randomised sampling and assignment of individuals to manipulated conditions, such as various conditions of stress, to contribute to more causal interpretability of results.

Another limitation was that the creativity task used in the study was quite general and only focused on one of the recognised dimensions of creativity (i.e. ideation). Future research should assess the associations found in this study using creativity tasks that are more specific in terms of the work context of the sample. For example, personnel from a marketing division of a firm might be assessed in generating new product development ideas or sales strategy formulation.

Finally, although statistically significant, the overall variance explained by the results of this study was relatively small. This could be attributable to a genuinely small effect, or to the method in which we measured creative task performance using the generic exercise, rather than measurement of creative task performance tailored to an actual work context. Future research needs to examine the relationship with more focused and different operationalisations of creativity. Despite these limitations, a notable strength of the study was its large sample and in the distinct methods for collecting independent and dependent variables in order to avoid common method issues for relationships between predictors and the outcome of creative task performance.

\section{CONCLUSION}

As managers seek ways to leverage human resources for competitive advantage, results of this study suggest the potential value of employees' character strengths. Specifically, the study results demonstrate a relationship between individuals' wisdom strengths and performance on a creative task. Such creativity may lead to innovation or to the implementation and adoption of new and useful ideas. Given the recognised importance of creativity to organisational success, these beginning research findings on the potential relationship of employee strength of wisdom with creativity should be noted by HRM scholars and practitioners. They also should explore whether to develop and nurture strengths such as wisdom in order to sponsor continuous learning opportunities (Staudinger et al., 1992; Smith et al., 1994). Indeed, wisdom may even be a means of expanding individuals' 'bounded rationality' (Simon, 1983) and promoting their creativity. This study provides initial empirical evidence for the important role that individuals' character strengths of wisdom and their level of stress may play in the creative process, leading to performance and competitive advantage through HRM.

\section{REFERENCES}

Amabile, T.M. (1996). Creativity in Context, Boulder, CO: Westview.

Amabile, T.M., Barsage, S.G., Mueller, J.S. and Staw, B.M. (2005). 'Affect and creativity at work'. Administrative Science Quarterly, 50: 3, 367-403.

Amabile, T.M., Conti, R., Coon, H., Lazenby, J. and Herron, M. (1996). 'Assessing the work environment for creativity'. Academy of Management Journal, 39: 5, 1154-1184.

Amabile, T.M., Hadley, C.N. and Kramer, S.J. (2002). 'Creativity under the gun'. Harvard Business Review, 80: 8, 52-61. 
Avey, J.B., Luthans, F. and Jensen, S. (2009). 'Psychological capital: a positive resource for combating employee stress and turnover'. Human Resource Management, 48: 5, 677-693.

Baer, M. and Oldham, G. (2006). 'The curvilinear relation between experienced creative time pressure and creativity: moderating effects of openness to experience and support for creativity'. Journal of Applied Psychology, 91: 4, 963-970.

Bandura, A. (1997). Self-Efficacy: The Exercise of Control, New York: Freeman.

Baron, R.M. and Kenny, D.A. (1986). 'The moderator-mediator variable distinction in social psychological research: conceptual, strategic, and statistical considerations'. Journal of Personality $\mathcal{E}$ Social Psychology, 51: 6, 1173-1182.

Basadur, M.S., Graen, G.B. and Green, S.G. (1982). 'Training in creative problem solving: effects on ideation and problem finding and solving in an industrial research organization'. Organizational Behavior and Human Performance, 30: 1, 41-70.

Beck, A.T., Emery, G. and Greenberg, R.L. (1985). Anxiety Disorders and Phobias: A Cognitive Perspective, New York: Basic Books.

Bunker, B.B. (1986). Management training in Japan: lessons for Americans. Proceedings, OD Network Conference, NY.

Chajut, E. and Algom, D. (2003). 'Selective attention improves under stress: implications for theories of social cognition'. Journal of Personality and Social Psychology, 85: 231-248.

Cooke, R.A. and Rousseau, D.M. (1984). 'Stress and strain from family roles and work role expectations'. Journal of Applied Psychology, 69: 2, 252-260.

Driskell, J.E. and Salas, E. (1991). 'Group decision making under stress'. Journal of Applied Psychology, 76: 3, 473-478.

Dweck, C.S., Higgins, E.T. and Grant-Pillow, H. (2003). 'Self-systems give unique meaning to self variables', in M. Leary and J. Tangney (eds), Handbook of Self and Identity, New York: Guilford Press.

Ellis, A.P.J. (2006). 'System breakdown: the role of mental models and transactive memory in the relationship between acute stress and team performance'. Academy of Management Journal, 49: 3, 576-589.

Elsbach, K.D. and Hargadon, A.B. (2006). 'Enhancing creativity through "mindless" work: a framework of workday design'. Organization Science, 17: 4, 470-483.

Fredrickson, B.L. (2001). 'The role of positive emotion in positive psychology: the broaden-and-build theory of positive emotions'. American Psychologist, 56: 3, 218-226.

George, A.L. (1986). 'The impact of crisis-induced stress on decision-making', in F. Solomon and R.Q. Marston (eds), The Medical Implications of Nuclear War, Washington, DC: National Academy of Sciences Press.

George, J.M. and Zhou, J. (2001). 'When openness to experience and conscientiousness are related to creative behavior: an interactional approach'. Journal of Applied Psychology, 86: 4, 513-524.

Hallowell, E.M. (2005). 'Overloaded circuits. Why smart people underperform'. Harvard Business Review, 83: 1, 54-62.

Hannah, S.T. and Luthans, F. (2008). 'A cognitive affective processing explanation of positive leadership: toward theoretical understanding of the role of psychological capital', in R.H. Humphrey (ed.), Affect and Emotion: New Directions in Management Theory and Research, Volume 7 of Research in Management, Charlotte, NC: Information Age.

Hannah, S.T., Woolfolk, R.L. and Lord, R.G. (2009). 'Leader self-structure: a framework for positive leadership'. Journal of Organizational Behavior, 30: 2, 269-290.

Harrison, D.A., Mohammed, S., McGrath, J.E., Florey, A.T. and Vanderstoep, S.W. (2003). 'Time matters in team performance: effects of member familiarity, entrainment, and task discontinuity on speed and quality'. Personnel Psychology, 56: 3, 633-669.

Hidi, S. and Harackiewicz, J.M. (2000). 'Motivating the academically unmotivated: a critical issue for the 21st century'. Review of Educational Research, 70: 2, 151-179.

Hobfoll, S. (2002). 'Social and psychological resources and adaptation'. Review of General Psychology, 6: $4,307-324$. 
Hunter, L.W. and Thatcher, S.M.B. (2007). 'Feeling the heat: effects of stress, commitment, and job experience on job performance'. Academy of Management Journal, 50: 4, 953-968.

Janis, I.L. (1972). Victims of Groupthink: A Psychological Student of Foreign-Policy Decisions and Fiascos, Boston, MA: Houghton Mifflin.

Lazarus, R.S. (1966). Psychological Stress and the Coping Process, New York: McGraw-Hill.

Locke, E.A. (1982). 'Relation of goal level to performance with a short work period and multiple goal levels'. Journal of Applied Psychology, 67: 4, 512-515.

Locke, E.A. and Latham, G.P. (1990). A Theory of Goal Setting and Task Performance, Englewood Cliffs, NJ: Prentice Hall.

Lord, R.G. and Brown, D.J. (2004). Leadership Processes and Follower Self-Identity, Mahwah, NJ: Lawrence Erlbaum.

Lovibond, P.F. and Lovibond, S.H. (1995). 'The structure of negative emotional stress: comparison of the depression anxiety stress scales (DASS) with the beck depression and anxiety inventories'. Behaviour Research and Therapy, 33: 3, 335-343.

Luthans, F. (2002). 'Positive organizational behavior: developing and managing psychological strengths'. Academy of Management Executive, 16: 1, 57-72.

Luthans, F. and Avolio, B.J. (2009). 'The point of positive organizational behavior'. Journal of Organizational Behavior, 30: 2, 291-307.

Luthans, F. and Youssef, C.M. (2007). 'Emerging positive organizational behavior'. Journal of Management, 33: 3, 321-349.

Luthans, F., Youssef, C.M. and Avolio, B.J. (2007). Psychological Capital: Developing the Human Competitive Edge, Oxford: Oxford University Press.

Mischel, W. and Shoda, Y. (1998). 'Reconciling processing dynamics and personality dispositions'. Annual Review of Psychology, 49: 1, 229-258.

Moos, R.H. and Schaefer, J.A. (1993). 'Coping resources and processes: current concepts and measures', in L. Goldberger and S. Breznitz (eds), Handbook of Stress, New York: Free Press.

Mumford, M.D. and Gustafson, S.B. (1988). 'Creativity syndrome: integration, application, and innovation'. Psychological Bulletin, 103: 1, 27-43.

Nelson, D.L. and Sutton, C. (1990). 'Chronic work stress and coping: a longitudinal study and suggested new directions'. Academy of Management Journal, 33: 4, 859-869.

Perry-Smith, J.E. (2006). 'Social yet creative: the role of social relationships in facilitating individual creativity'. Academy of Management Journal, 49: 1, 85-101.

Peterson, C. and Seligman, M.E.P. (2003). 'Character strengths before and after September 11'. Psychological Science, 14: 4, 381-384.

Peterson, C. and Seligman, M.E.P. (2004). Character Strengths and Virtues: A Handbook and Classification, New York: Oxford University Press/Washington, DC: American Psychological Association.

Phillips, J.M. and Gully, S.M. (1997). 'Role of goal orientation, ability, need of achievement, and locus of control in the self-efficacy and goal-setting process'. Journal of Applied Psychology, 82: 5, 792-802.

Salas, E., Driskell, J.E. and Hughes, S. (1996). 'Introduction: the study of stress and human performance', in J.E. Driskell and E. Salas (eds), Stress and Human Performance, Mahwah, NJ: Erlbaum.

Sansone, C., Weir, C., Harpster, L. and Morgan, C. (1992). 'Once a boring task always a boring task? Interest as a self-regulatory mechanism'. Journal of Personality and Social Psychology, 63: 3, 379-390.

Schmidt, A.M. and Ford, K.J. (2003). 'Learning within a learner control training environment: the interactive effects of goal orientation and metacognitive instruction on learning outcomes'. Personnel Psychology, 56: 2, 405-429.

Seligman, M.E.P. and Csikszentmihalyi, M. (2000). 'Positive psychology: an introduction'. American Psychologist, 55: 1, 5-14.

Shalley, C.E., Zhou, J. and Oldham, G.R. (2004). "The effects of personal and contextual characteristics on creativity: where should we go from here?' Journal of Management, 30: 6, 933-958.

Shipton, H., West, M.A., Dawson, J., Birdi, K. and Patterson, M. (2006). 'HRM as a predictor of innovation'. Human Resource Management Journal, 16: 1, 3-27. 
Simon, H.A. (1983). Reason in Human Affairs, Stanford, CA: Stanford University Press.

Smith, J., Staudinger, U.M. and Baltes, P.B. (1994). 'Occupational settings facilitating wisdom-related knowledge: the sample case of clinical psychologists'. Journal of Consulting and Clinical Psychology, 62: 5, 989-999.

Staudinger, U.M., Smith, J. and Baltes, P.B. (1992). 'Wisdom-related knowledge in a life review task: age differences and the role of professional specialization'. Psychology and Aging, 7: 2, 271-281.

Staw, B.M., Sandelands, L.E. and Dutton, J.E. (1981). 'Threat-rigidity effects in organizational behavior: multi-level analysis'. Administrative Science Quarterly, 26: 4, 501-524.

Tierney, P. and Farmer, S.M. (2002). 'Creative self-efficacy: potential antecedents and relationship to creative performance'. Academy of Management Journal, 45: 6, 1137-1148.

Tsai, W.C., Chen, H.W. and Cheng, J.W. (2009). 'Employee positive moods as a mediator linking transformational leadership and employee work outcomes'. The International Journal of Human Resource Management, 20: 1, 206-219.

Wood, R. and Bandura, A. (1989). 'Impact of conceptions of ability on self-regulatory mechanisms and complex decision making'. Journal of Personality and Social Psychology, 56: 3, 407-415.

Wright, T.A. and Goldstein, J. (2007). 'Character is not "dead" in management research: a review of individual character and organizational-level virtue'. Journal of Management, 33: 6, 928-958. 